\title{
História de uma Instituição Escolar: democratização ou elitização do ensino secundário (1939-1971)?
}

\author{
Eurize Caldas Pessanha*
}

Fabiany de Cassia Tavares Silva ${ }^{* *}$

\section{Resumo}

Este artigo resulta de pesquisa inserida no campo da história das instituições, com foco na reescrita da história do ensino secundário. Nesse contexto, busca-se compreender o processo histórico de implantação e consolidação do ensino secundário em uma instituição escolar do sul do estado de Mato Grosso, no período de 1939 a 1971. Período esse determinado pelo início do funcionamento e pela Lei no 5692, de 1971, que alterou a organização do ensino primário e do secundário, eliminando o ginásio. Para tanto, a operação metodológica alia dados de pesquisa bibliográfica relativa à temática, ensino secundário, a partir da seleção e análise de livros, capítulos de livros, artigos, dissertaçôes e teses. Essas últimas, localizadas pelo objeto de estudo a que se dedicaram, isto é, a instituição de que trata este texto. Acresce-se a esse exercício, dados de pesquisa documental para a qual foram selecionados como fontes os documentos localizados no arquivo escolar do Colégio Campograndense: Atas da Congregação; Livros de atas; Livros de inscrição de exames de admissão à $1^{\text {a }}$ série do Curso Ginasial; Livros de matrícula; Livro de registro de professores. Em conclusão, aponta-se que a história dessa instituição indica que a "democratização" dos ginásios contribuiu para ascensão social das classes médias urbanas escolarizadas que, ao se apropriarem desse "luxo", habilitaram-se a se inserir nos grupos dirigentes.

Palavras-chave: Instituiçóes Escolares. Ensino Secundário. Democratização do Ensino.

\footnotetext{
* Doutora em Educação pela Universidade de São Paulo (USP). Professora do curso de Pedagogia e da Pós-Graduação em Educação na Universidade de Mato Grosso do Sul (UFMS).

${ }^{* *}$ Doutora em Educação pela Pontifícia Universidade Católica de São Paulo (PUC/SP). Professora do curso de Pedagogia e da Pós-Graduação em Educação na Universidade de Mato Grosso do Sul (UFMS).
} 


\section{Notas Introdutórias}

Este texto resulta de pesquisa inserida no campo da história das instituiçôes, com foco na reescrita da história do ensino secundário, a partir de uma hipótese central, a saber: as diferentes reformas pelas quais passou este nível de ensino pareceram revesti-lo de condiçâo de mecanismo de ascensão social, uma espécie de democratização do acesso, mas que, em última instância, auxiliou na formação de grupos dirigentes.

Esse processo vem sendo identificado como dualismo em pesquisas sobre o tema (DALLABRIDA; CARMINATI, 2007; NUNES, 2000), configurado na divisão em dois ramos, um destinado às individualidades condutoras e outro que habilitava profissionais aos diversos setores da economia, como resposta às necessidades modernas da sociedade urbana. Para tanto, o Estado brasileiro formulou currículos mínimos obrigatórios, conteúdos nacionais ou "nacionalistas" transmitidos nas escolas, livros didáticos e outros, criando um sistema federal de regulação e controle das instituiçóes pelo país, regulação essa operada pela verificação da aplicabilidade da legislação em vigor.

Nesse contexto, buscamos compreender o processo histórico de implantação e consolidação do ensino secundário em uma instituição escolar do sul do estado de Mato Grosso no período de 1939 a 1971, que era determinado pelo início do funcionamento da escola, o Liceu Campograndense, em Campo Grande, Mato Grosso, e pela Lei n ${ }^{\circ}$ 5692, de 1971, que alterou a organização do ensino primário e do secundário, eliminando o ginásio (BRASIL, 1971). Essa instituição representou, neste espaçotempo histórico e educativo, o primeiro ginásio público da cidade e a possibilidade de ampliação de escolaridade para além do ensino primário; além disso, ao inaugurar sua sede própria em edifício projetado por Oscar Niemeyer, tornou-se marco arquitetônico da cidade e indutor de uma forma escolar para além dos muros da escola, em uma relação de representação da cidade.

Magalhães (2004) distingue duas orientaçôes comuns na historiografia da educação tomando por base as instituiçōes: primeiro, a história das suas relaçóes com a sociedade, seu papel social, suas influências e determinaçóes; segundo, sua história na sua singularidade, em suas características e relaçōes internas e suas práticas.

Nossa proposta está fundada na segunda orientação: a construção desse colégio como objeto historiográfico específico, estudado na sua 
multidimensionalidade e em seus fatores internos, destacando-se como elemento central dessa construção a articulação de seu projeto educativo com a produção de uma escolarização altamente seletiva. Dessa forma, a operação metodológica reúne dados de pesquisa bibliográfica relativa à temática, ensino secundário, a partir da seleção e análise de livros, capítulos de livros, artigos, dissertações e teses. Essas últimas, localizadas pelo objeto de estudo a que se dedicaram, isto é, a instituição de que trata este texto. Acresce-se a esse exercício, dados de pesquisa documental para a qual foram selecionados como fonte os documentos localizados no arquivo escolar do Liceu Campograndense: Atas da Congregação; Livros de atas; Livros de inscrição de exames de admissão à $1^{\text {a }}$ série do Curso Ginasial; Livros de matrícula; Livro de registro de professores.

Para a apresentaçáo de nosso processo investigativo organizamos duas partes relativamente autônomas, mas complementares. A primeira incursiona, de forma pontual, pelo campo da pesquisa em história do ensino secundário apontando os pressupostos voltados para a escolarização das elites. A segunda trata da hipótese dessa elitização desenhada em um ensino secundário de uma instituição específica.

\section{Ensino Secundário no Brasil: breves indícios da produção de uma escolarização para as elites}

O ensino secundário no Brasil teve início de forma sistemática em 1837, após a criação do Imperial Collegio de Pedro II fundado, segundo Vecchia (2006, p. 58) "com a finalidade de educar a elite intelectual, econômica e religiosa brasileira e, concebido para ser o centro difusor das ideias educacionais, relativas ao ensino secundário". Oficializado por decreto de 2 de dezembro de 1837, por iniciativa do Ministro da Justiça e interino do Império, Bernardo Pereira de Vasconcellos, indicava uma opçáo pelo modelo francês de ensino secundário (HAIDAR, 2008).

Desde então, o ensino secundário passou por várias reformas, em âmbito nacional, durante a Primeira República: Benjamin Constant (1890), Epitácio Pessoa (1901), Rivadávia Correa (1911), Carlos Maximiliano (1915) e João Luiz Alves (1925); e na chamada Era Vargas mais duas reformas, Francisco Campos (1931) e Gustavo Capanema (1942), que reformularam o seu currículo.

Em 1890, a reforma implementada por Benjamin Constant, por meio do Decreto no 981 , de 8 de novembro, de clara orientaçáo positivista e baseada 
na racionalidade técnica e na investigação experimental, conforme os modelos europeus, buscou a formação científica na educação secundária.

Segundo Zotti (2004, p. 75), o objetivo dessa Reforma

[...] nada mais representou do que a necessidade de modernizar a formação da elite, fazendo uso das ciências modernas em prol da erudição e do verbalismo, reforçando o carácter enciclopédico e propedêutico do ensino. Contudo, não se efetivou nos moldes de seus idealizadores, pois, de 1891 a 1900 , uma sequência de decretos, regulamentos, portarias, instruçōes e avisos modificam substancialmente o plano de estudos e o regime de equiparação adotados por Benjamim Constant.

Até a reforma de ensino organizada por João Luiz Alves, em 1925, a qualificação para exames preparatórios, com estudos irregulares e assistemáticos, bem como a preponderância da finalidade propedêutica sobre a formativa, continua a funcionar como alternativa da escolarização secundária regular, tanto no ensino público como no particular.

O ensino secundário no Brasil teve uma propagação lenta que, iniciada no império, só foi se expandir sistematicamente na década de 1950, consolidando sua estruturaçáo como curso apenas com a Reforma Francisco Campos, em 1931. Além de lenta, essa propagação teve em seu início pouca participação do poder público por ser considerado um luxo aristocrático a ser deixado à iniciativa privada (ALMEIDA apud SPOSITO, 1984).

A adoçáo desse princípio pode ser observada no Estado de São Paulo, cuja rede de estabelecimentos de ensino secundário públicos compreendia, até a década de 1930, no Ginásio do Estado, criado em 1892, na capital e dois outros no interior, um em Ribeirão Preto e outro em Campinas. Dados semelhantes são encontrados no Estado do Rio de Janeiro, Minas Gerais, Mato Grosso e Santa Catarina (NUNES, 2000; DALLABRIDA; CARMINATI, 2007).

$\mathrm{Na}$ década de 1940, Capanema confirmou, na Exposição de Motivos do Decreto-Lei 4244, de 9 de abril de 1942, que o caráter específico desse nível de ensino se define pela sua função de formar adolescentes com uma sólida cultura geral, marcada tanto pelas humanidades antigas quanto pelas humanidades modernas, e com elevada consciência patriótica e humanística (BRASIL, 1952). 
Trata-se, portanto, de uma proposta de escolarização para os grupos dirigentes, "um luxo" a que o governo não destina seus recursos. Ao restringir as possibilidades de acesso ao ensino superior aos poucos estabelecimentos de ensino secundário, em sua maioria, particulares, e conferir terminalidade real aos cursos técnico-profissionais, determinava-se a desigualdade de trajetórias segundo a origem social, com "raras exceçôes" (DALLABRIDA; CARMINATI, 2007, p. 19).

$\mathrm{Na}$ esteira da consolidação do poder político das "classes médias urbanas" no Brasil, bens de consumo típicos dessa classe, entre os quais, a educação, fazia parte da pauta de demandas desses grupos. Inicialmente essa pauta se restringia à universalização do ensino primário e o aumento da matrícula nesse nível de ensino é um indicativo de que suas demandas foram atendidas, uma vez que, de pouco mais de 1 milhão de matrículas em 1920, chega-se a mais de 7 milhóes em 1960. A partir da metade dos anos 1940, essa pauta incluía a extensão vertical da educação, exigindo do Estado o "luxo aristocrático" do ensino secundário, principalmente o ginásio (SPOSITO, 1984).

No modelo curricular adotado pela Reforma Rocha Vaz de 1925, a seriação encontra-se no art. 47 , onde se lê: "o ensino secundário como prolongamento do ensino primário para fornecer a cultura média geral do paiz" (BRASIL, 1925).

Em 1931, o ministro da Educação e Saúde Pública baixou um conjunto de cinco decretos, conhecidos como Reforma Francisco Campos ${ }^{1}$. Considerada a mais importante na história da renovação da educação brasileira. Essa Reforma, segundo Souza (2008, p. 147), "sinalizou os rumos da ação do Estado na tentativa de constituição de um sistema nacional de educação pautado nos princípios da racionalidade e uniformização".

$\mathrm{Na}$ Exposição de Motivos que fundamenta o Decreto n. 19.890, Francisco Campos (BRASIL, 1952) realiza uma análise criteriosa e qualifica o ensino secundário como "simples instrumento de preparação dos candidatos ao ensino superior, desprezando assim, a sua função eminentemente educativa". Campos (1931, p. 406) ainda acentua que: "[...] o ensino superior acabou por transformar-se em uma finalidade puramente extrema e convencional do ensino secundário, isto é, este, finalmente dominado pela absorvente preocupação do primeiro". Argumenta ainda que para a "reconstrução do ensino secundário" era necessário "conferir-lhe, de modo distinto e acentuado, um carácter eminentemente educativo" (BRASIL, 1952, p. 406). 
A década de 1940 assiste a uma grande expansão no número de matrículas no ensino secundário, passa de 170.000 alunos, em 1930, para 260.000, em 1940. Em abril de 1942, o ministro da educação, Gustavo Capanema, responsável por uma completa reviravolta no ensino secundário, promulga a Reforma Capanema. Esta Reforma modifica a Reforma Francisco Campos, de1930, principalmente na concepção do ensino secundário, o que fica entendido no discurso da exposição de motivos, isto é, não se trata mais de educar o indivíduo, mas conduzir as massas.

A reforma atribui ao ensino secundário sua finalidade fundamental, que é a formação da personalidade do adolescente.

[...] socializá-lo constitui finalidade de toda espécie de educação. O que constitui o caráter específico do ensino secundário é sua função de formar nos adolescentes uma sólida cultura geral, marcada pelo cultivo a um tempo das humanidades antigas e das humanidades modernas, e bem assim de neles acentuar e elevar a consciência patriótica e a consciência humanística. [...] o ensino secundário se destina à preparação das individualidades condutoras, isto é, dos homens que deverão assumir as responsabilidades maiores dentro da sociedade e da nação, dos homens portadores das concepçóes e atitudes que é preciso infundir nas massas, que é preciso tornar habituais entre o povo. (BRASIL, 1952, p. 23).

Distinções significativas entre essas duas proposições de especificidade do ensino secundário, ou seja, a formação da sólida cultura geral e as consciências patriótica e humanística, se dão tanto no plano de sua concepção, como uma instituição detentora de finalidades sociais, como no $e t h o s^{2}$, que contribui para a determinação do nível cultural e escolar almejado pelos/para os indivíduos. Para tanto, o Estado brasileiro formulou currículos mínimos obrigatórios, conteúdos nacionais ou "nacionalistas" transmitidos nas escolas, livros didáticos e outros, criando um sistema federal de regulação e controle das instituiçôes pelo país, regulação essa operada pela verificação da aplicabilidade da legislação em vigor. 


\section{Ensino Secundário: reescrita a partir de uma hipótese de pesquisa, a elitização do Colégio Campograndense ${ }^{3}$ (1939- 1971)}

Em 1939, de acordo com o Decreto-Lei no 229, de 27 de novembro de 1938, instalava-se o primeiro ginásio público campo-grandense, denominado, na época, Liceu Campograndense. Em 1942, o seu nome mudou para "Ginásio Campograndense", por meio do Decreto no 101, de 27 de abril.

Os representantes da regiáo sul do Estado reclamavam que o governo não priorizava a educação para essa região que contava, até a década de 1920 , com nove estabelecimentos de Ensino Primário, sendo seis estaduais e três municipais.

O ensino secundário foi, inicialmente, ministrado apenas em três escolas particulares, duas delas ligadas à Igreja Católica: o Colégio D. Bosco (masculino), o Colégio Nossa Senhora Auxiliadora (feminino), e uma escola não confessional o Colégio Oswaldo Cruz.

A instalação do primeiro ginásio público, o Liceu Campograndense, em 1939, resultou de mobilização política fundada na justificativa de que muitas famílias não tinham condiçôes de pagar para que seus filhos ampliassem sua escolaridade até o ginásio. Registre-se que a criação se deu em meio ao crescimento da cidade (a implantação da Estrada de Ferro Noroeste do Brasil) e por iniciativa de uma professora cuiabana ${ }^{4}$, com notória participação política, que liderou uma mobilizaçáa junto ao governo do Estado para instalar o primeiro ginásio público da cidade: "[...], propus ao interventor Júlio Muller e ao Dr. João Ponce de Arruda, secretário de Fazenda do Estado, a criação de um ginásio estadual que pudesse resolver os problemas dos que precisavam continuar a estudar e não tinham meios de pagar a escola" (MACHADO apud ROSA, 1990, p. 64).

Já no final da década de 1930, o estabelecimento contava com algumas normalistas, entre elas a professora Maria Constança Barros Machado, os demais professores não possuíam graduação específica para o magistério, eram profissionais de diferentes áreas, como médicos, militares com cursos do exército, sacerdotes, religiosas e demais profissóes.

Nas fichas de cadastro docente, apenas uma professora está registrada como professora em exercício desde 1939, em outra instituição, que funcionava no mesmo endereço (CAMPO GRANDE, 1939). De acordo com os registros da 
vida profissional de cada um, percebe-se que a maioria ingressou como interino, permaneceu por pouco tempo na escola e não possuía Registro no Ministério da Educação e Cultura (MEC). Esse registro foi, em sua maioria, resultado do Exame de Suficiência realizado após os cursos da Campanha de Aperfeiçoamento e Divulgação do Ensino Secundário (CADES), órgão vinculado ao MEC.

O início das atividades regulares, ou melhor após inspeção prévia, se deu apenas em 1942, ano em que o Liceu passou a chamar Colégio Campograndense, com 10 professores (sete homens e três mulheres), sendo seis deles registrados no MEC.

Quanto à admissão dos docentes, as fontes acessadas (CAMPO GRANDE, 1939; ADIMARI, 2005; BRAGA, 2006) indicam certa estabilidade, uma vez que ocorria, geralmente, por indicação de outro professor da escola. Acrescenta-se a essa ideia, a de que os professores incorporados consideravam uma honra ser professor daquela escola. Tal ideia é corroborada em outros registros, que dáo conta do destaque dado pelos alunos a excelente qualidade o corpo docente.

O depoimento de uma professora da época confirma essa ideia, pois, para ela: "[...] era uma honra dar aulas naquela escola, os professores geralmente eram indicados por outras pessoas, pois era uma escola muito conceituada e precisava cuidar para que o quadro de professores fosse da melhor qualidade" (ADIMARI, 2005, p. 107).

Para o ano letivo de 1939, de acordo com o Artigo 6o do Decreto 229 (MATO GROSSO, 1938), estava previsto o funcionamento apenas da $1^{\text {a }}$ série do curso fundamental, na qual deveriam ser matriculados os candidatos aprovados no Exame de Admissão, conforme as exigências do Decreto Federal $\mathrm{n}^{\circ}$ 21.241, de 4 de abril de 1932 (BRASIL, 1932).

Os alunos que quisessem estudar no primeiro ginásio público da cidade precisavam submeter-se aos então denominados Exames de Admissão ao Ginásio, obrigatórios para o ingresso no ensino secundário. Vale destacar que, pelo seu caráter público, seria uma escola voltada para atender às famílias que não podiam pagar para seus filhos estudarem nos ginásios particulares já existentes. Esses alunos seriam, em sua maioria, filhos de operários e funcionários públicos que não tinham condiçôes de ampliar a escolaridade para além do curso primário.

Assim, o Colégio parecia ser percebido como um espaço de "compensação" para uma desvantagem inicial, rompendo a circularidade da reproduçáo. Dito 
de outro modo, se usasse todos os seus recursos pedagógicos com intuito de atender todos os estudantes, ele poderia colocar em condiçóes de igualdade, ou menos desiguais, para aqueles que chegam até o Colégio desprovidos ou, talvez, menos providos de capital cultural.

O Ginásio Campograndense realizava os exames de admissão com provas escritas para Português, Aritmética e provas orais para as disciplinas de Geografia Geral e do Brasil, Desenho, Ciências e História Geral e do Brasil.

Segundo depoimentos da ex-professora e ex-diretora do Colégio, Profa. Maria Constança, "havia briga entre as famílias para conseguir uma vaga" (BITTAR; FERREIRA JÚNIOR, 1999, p. 179). Tal situação exemplifica que a busca das camadas populares pelo oferecimento aos alunos da capacidade de desfrutar os bens da cultura erudita seria um fator distintivo.

A Constituição de 1937 previa o atendimento à juventude de baixo poder aquisitivo, mas o ginásio não comportava "bancos escolares para todos". Diante disso, em conformidade com a Lei Orgânica de 1942, artigo 21 (BRASIL, 2008), o colégio passou a realizar um processo de seleçáo rigorosa e seletiva com os chamados exames de admissão. Dados de depoimentos de ex-alunos (BRAGA, 2006) confirmam as informaçóes de que os exames de admissão determinavam ao Colégio a imagem de que se destinava para "muito poucos". Para o primeiro exame de admissão, realizado em 1939, inscreveram-se 50 candidatos e 37 foram aprovados. No período estudado, o percentual máximo de aprovados no exame de admissão foi de 67\%, em 1945, e em 1958, registrouse o menor índice (26\%).

Contraditoriamente, os candidatos de renda alta e média-alta tinham melhores condiçôes de enfrentar os exames de admissão, por estarem mais bem preparados, pois, além de terem cursado os quatro do ensino primário, ainda frequentavam durante um ano inteiro os denominados cursos preparatórios para os exames de admissão.

Nesse contexto, alunos e professores, com o objetivo de aceitação na instituição, acabavam reproduzindo as sequências de açóes geradoras da cultura escolar, delineadas na presença do habitus de classe, apesar das contradiçóes e desajustes vividos nas práticas escolares. Quando a referência é feita ao Colégio, é este o sentido que está sendo dado à escola e suas práticas.

Em depoimento uma ex-aluna observa que: 
Eu cursei o Ginásio no Campo-Grandense. Os professores não possuíam formação específica, em sua maioria, mas eram competentes, compromissados com o mister de ensinar, pontuais, esforçados e exigentes quanto ao estudo dos alunos. Eram, também, verdadeiras autoridades. (ADIMARI, 2005, p. 109).

Bourdieu (1996) compreende que os agentes sociais estão inseridos espacialmente em determinados campos sociais, a posse de grandezas de certos capitais (cultural, social, econômico, político, artístico, esportivo etc.) e o habitus de cada agente social condiciona seu posicionamento espacial e, na luta social, identifica-se com sua classe social. Esse mesmo autor afirma que, para o ator social tentar ocupar um espaço, é necessário que ele conheça as regras do jogo dentro do campo social e que esteja disposto a lutar (jogar).

Se na década de 1930 a inovação fora a própria criação da escola, único ginásio público da cidade, resultado da mobilizaçáo da comunidade liderada pela professora Maria Constança Barros Machado, na década de 1950 trouxe duas inovaçóes que alteraram profundamente a configuração de alunos e professores: a criação do segundo ciclo do curso secundário (científico) e a mudança para a sede própria, um edifício projetado por Oscar Niemeyer que se tornou um marco na arquitetura da cidade.

Tornado-se um marco do ensino na cidade, principalmente devido ao caráter seletivo e à intensa competição dos exames de admissão, novamente graças à mobilizaçáo de sua diretora Maria Constança Barros Machado, o Colégio se propôs a atender à aspiraçáo da cidade por ampliaçáo das oportunidades educacionais.

A lógica das instituiçóes de ensino, porque náo dizer do sistema de ensino, é servir de instrumento de legitimação das desigualdades sociais. Dito de outra forma, mantém a dominação dos dominantes sobre as classes populares, sendo representada como um instrumento de reforço das desigualdades e como reprodutora cultural, para qual o acesso à cultura é desigual segundo a origem de classe. Assim é que, em 1953, é criado o segundo ciclo do ensino secundário (científico) "creação essa que toda a população da cidade vinha ansiosamente esperando e pedindo desde vários anos". (CAMPO GRANDE, 1953). 
Da mesma forma que a criação do primeiro ginásio público da cidade, a extensão do oferecimento dos estudos em uma escola pública ao segundo ciclo do ensino secundário foi resultado de mobilização política e sua instalação foi registrada com a deferência merecida.

Em sessão solene "sob a presidência do Sr. Dir. Fernando Corrêa da Costa, Governador do Estado, demais autoridades civis e militares, corpo docente e discente e numerosa assistência” (CAMPO GRANDE, 1953).

A instalação do segundo ciclo do curso secundário foi autorizada pelo Ministério de Educação e Saúde, em 31 de março de 1953, com isso o Colégio passou a ser denominado "Colégio Estadual de Campo Grande" e o curso científico, uma das modalidades do segundo ciclo do ensino secundário, iniciou com uma turma de 24 alunos.

A organização desse curso obedecia à Lei Orgânica do Ensino Secundário de 1942 que estabelecia como objetivos desse nível de ensino:

[...] consolidar a educação ministrada no curso ginasial e bem assim desenvolvê-la e aprofundá-la. No curso clássico, concorrerá para a formaçáo intelectual, além de um maior conhecimento de filosofia, um acentuado estudo das letras antigas; no curso científico, essa formaçâo será marcada por um estudo maior de ciências. (BRASIL, 2008).

Um grande fator de inovação parece ter sido a possibilidade da continuação dos estudos para as mulheres no "científico", aumentando o leque de ofertas, uma vez que os outros estabelecimentos, todos particulares, só eram abertos ao sexo masculino. Em Rahe (2006), encontramos o depoimento de uma ex-aluna da década de 1950, que fizera sua formaçáo anterior em uma escola religiosa feminina, ao ser indagada sobre a razão da mudanças e manifesta:

O Maria Constança era o único científico da cidade ou você estudava lá ou ia pra fora. O Colégio Osvaldo Cruz tinha o contador, tinha o científico no Dom Bosco mas era só masculino, então mulher não tinha aonde estudar, ou fazia normal ou contador [...]. Nós queríamos fazer o científico, normal não, contador muito menos. A gente queria fazer o científico que dava uma abertura prá fazer vestibular para um curso de exatas, de engenharia, de 
agronomia. Então, a gente queria um leque assim, com o científico e náo com o contador ou normal. (RAHE, 2006, p. 35).

Em acréscimo a essas informações, pode-se perceber que havia seletividade no processo de ingresso dos alunos: "Quando eu consegui entrar lá, na verdade, eu nem sei como eu consegui, porque eu fiquei na fila de espera até a véspera do início das aulas, eu e uma amiga, por não conseguirmos vaga nós estávamos vendo para ir para São Paulo, porque não tinha aonde estudar" (RAHE, 2006, p. 35).

Essa seletividade, que caracterizava o nível de exigência da escola, não se restringia à dificuldade de ingresso, mas continuava a ser percebida durante o curso, obrigando alunos que vinham de escolas "menos exigentes" a procurarem alternativas para conseguir acompanhar o nível da nova escola:

[...] quando eu entrei lá, minha mãe teve que arrumar professor particular de matemática, porque metade do curso de matemática não tinha sido dado no outro colégio, [...], onde estudei, tive dificuldades porque muitos assuntos tinham sido passados por cima, principalmente em matemática e ciências, que deveriam ter dado noçóes de química e física tanto que quando eu entrei lá, minha mãe teve que arrumar professor particular de matemática, porque metade do curso de matemática não tinha sido dado no outro colégio, no Auxiliadora, onde estudei, tive dificuldades porque muitos assuntos tinham sido passados por cima, principalmente em matemática e ciências, que deveriam ter dado noçóes de química e física. (RAHE, 2006, p. 131).

A "excelência" dos professores continuava sendo reiterada, acrescida agora pela mençáo à sua "boa vontade" por terem aceitado assumir as aulas do curso científico sem receber acréscimo em sua remuneração.

No ano seguinte à instalação do científico, o caráter inovador do Colégio Estadual acentuou-se com sua transferência para uma sede própria, inaugurado em sessão solene, com a presença de autoridades, no dia 25 de setembro de 1954, mencionada pela imprensa local: "Em 26 de agosto próximo deverá ser inaugurado o novo prédio do Ginásio Estadual Campograndense, uma das 
realizações do Governo que a União Democrática Nacional em boa hora, levou ao poder!" (CORREIO... apud BRAGA, 2006, p. 18).

Embora já fosse importante o fato de deixar as instalaçóes anexas ao Grupo Escolar Joaquim Murtinho onde funcionou desde a sua criação, o Colégio Estadual transferiu-se para um edifício que se tornaria um marco na arquitetura da cidade. Edifício projetado por Oscar Niemeyer que havia elaborado o projeto para a cidade de Corumbá, na época, mais importante do que Campo Grande e, por determinação do Governador, a pedido da direção da escola, o projeto foi repetido em Campo Grande.

A escolha do lugar para a construção não parece ter sido gratuita, pois a Rua Y Juca Pirama, no bairro Amambaí, regiâa conhecida pelos moradores como "Cabeça de Boi", de moradia operária, ligava a área central da cidade com a parte oeste, onde estavam situados os quartéis militares. Informaçóes coletadas em jornais da época, indicavam uma disputa entre as forças políticas locais e as forças ligadas ao governador, com maior votação exatamente neste bairro, razão pela qual foi escolhido para a construção do Colégio Estadual (BRAGA, 2006).

O edifício foi tombado pelo Patrimônio Histórico do Estado em 1996, e suas características arquitetônicas evidenciavam os elementos do modernismo e contribuíram para a sua "monumentalidade", conferindo visibilidade e uma espécie de "perenidade" aos projetos dos grupos que se consideravam elite na cidade (PESSANHA; ARRUDA, 2008).

O programa criado pelo arquiteto tinha oito salas de aula com apoio didático, laboratórios, auditório com 250 lugares para palestras, reuniōes e espaços de encontros. As salas de aula possuíam duas fitas de janelas envidraçadas, sendo uma na parte superior, para retirar ar quente e a outra na altura da mesa do aluno, para a renovaçáo de ar, além de integrar o espaço da sala com o jardim externo. As formas arquitetônicas puras e retas eram quebradas com elementos internos, como o balcão sinuoso do refeitório ou o mastro da bandeira e a caixa d'água cujo formato lembrava um giz.

A obra utilizava técnicas construtivas simples, como o tijolo na circulação das salas de aula, tipo cobogó, ou arrojadas, como a cobertura de concreto no pátio de recreio. O edifício estava organizado em partes interligadas por passarelas cobertas com laje plana, a partir dos espaços funcionais do bloco de serviços, salas de aula e administrativo, pátio coberto, auditório e guarita 
de entrada. A planta foi organizada de forma modulada, usando um sistema estrutural de pilares de forma cilíndrica, típico da arquitetura brasileira dos anos 1940 e 1950, em sistema modulado que vai definindo a malha construtiva.

No ano seguinte à sua inauguração, foi realizada a Inspetoria do Colégio Estadual Campograndense com vistas à autorização de funcionamento. $\mathrm{O}$ Relatório de Verificação (CAMPO GRANDE, 1956), elaborado como resultado dessa Inspeção, apresentava avaliação muito positiva do edifício, concedendo nota 10 ao quesito Material e Conservação, registrando "Os edifícios são de construção moderna em cimento armado (Projeto Oscar Niemeyer)".

O impacto dessa construção moderna em uma cidade "caipira" foi registrado por alunos e professores. Braga (2005) registrou o depoimento de uma ex-aluna que fez questão de informar: "Eu fui da primeira turma que começou no prédio novo, em 1954. Como eu era a menor da turma da $1 .^{a}$ série, no dia da inauguração eu fui a portabandeira. Estudei os quatro anos do ginásio e os três do Colegial”.

Esse impacto parece ter perdurado até hoje. Braga, (2006, p. 11) descreveu como em sua memória ficou registrado seu primeiro encontro com o edifício:

Foi em 1974 que subimos, pela primeira vez, a rampa de acesso à Escola Estadual Maria Constança Barros Machado. Um prédio diferente de muitos outros que pela cidade se viam e que, por algum tempo, mais exatamente de 1954 a 1971, se denominou Colégio Estadual Campograndense. Sonho de muitas crianças, adolescentes e jovens, tamanho privilégio de nele poder estudar, dado o conceito de seu bom ensino ministrado.

Continuando na mesma rampa, chegávamos ao corpo do edifício propriamente dito. No centro ficava a secretaria, à direita ficava a sala da diretoria, supervisão e dos professores, à esquerda ficavam as salas de aula, em número de oito, distribuídas ao lado direito de um longo corredor com tijolos vazados; do lado esquerdo, no fim do corredor um laboratório que mais tarde virou sala de aula também. Desse corredor, saía o acesso aos banheiros, cantina e quadras esportivas. 
Outro local que atraia muito a atenção em relaçáo à fachada da escola era o espaço livre que ficava do lado direito, gramado e com muitas árvores, porém esse espaço era muito pouco utilizado, não era um espaço disputado. Apesar de que, nas raras oportunidades em que havia alguma atividade fora da sala, o pátio gramado era usado.

Segundo Bourdieu (1996), a instituição escolar auxilia na produção de esquemas de apreciação, percepção e ação do mundo social por via da internalização dos sistemas classificatórios dominantes no mundo social global. E, no depoimento está retratado um conjunto de disposiçóes que se acumularam ao longo da vida e que se devem à origem e à trajetória escolar. Ele é produto da incorporação da necessidade, uma espécie de natureza, porém uma natureza socialmente construída, por que não dizer habitus: "[...] produto da história, o habitus produz práticas, individuais e coletivas, e, portanto história em conformidade com os esquemas engendrados por essa mesma história" (BOURDIEU, 2002, p. 178).

\section{Considerações Finais}

Embora tenha sido criado com a justificativa de que era necessário atender a famílias sem condiçóes de pagar os estudos de seus filhos nos ginásios particulares, o Colégio Campograndense tornou-se, contraditoriamente, altamente seletivo, é uma escola para "poucos e seletos" professores e alunos. Essa seletividade constituiu parte importante na sua definiçáo como uma "escola exemplar", uma escola que, expressava os projetos de modernização e escolarização daqueles grupos.

Nesse sentido, pode-se entender essa exemplaridade como produto da adequação dessa instituição às expectativas da sociedade à qual servia, já que o ensino secundário, como o ofertado, deu forma a uma das estratégias de acúmulo de prestígio e capital cultural. Vale destacar, que essas estratégias também eram dependentes da extensão da rede de relaçóes que poderia subsidiar o interreconhecimento dos indivíduos e grupos, essencial para a multiplicação do capital social.

A história indicou que a "democratização" dos colégios contribuiu para ascensão social das classes médias urbanas escolarizadas que, ao se apropriarem desse "luxo", habilitaram-se a se inserir nos grupos dirigentes. 
Para finalizar, cabe ressaltar que tal apropriação acabou por destacar o papel do capital social na configuração dos ex-agentes discentes e docentes, ou seja, a frequência no Colégio Campograndense também resultou, em parte, na intensidade das relaçóes sociais cultivadas em suas famílias e ao alto valor dado às relações interpessoais.

\section{Notas}

1 Decreto n. 19.850, de 11 de abril de 1931: cria o conselho Nacional de Educação; Decreto n. 19.851, de 11 de abril de 1931: dispóe que o ensino superior no Brasil obedecerá, de preferência, ao sistema universitário; Decreto n. 19.852, de 11 de abril de 1931: dispóe sobre a organização da Universidade do Rio de Janeiro; Decreto n. 19.890, de 18 de abril de 1931: dispóe sobre a organizaçáo do ensino secundário; e Decreto n. 20.158, de 30 de junho de 1931: organiza o ensino comercial, regularmente a profissão de contador e dá outras providências.

2 " [...] sistema de valores implícitos e profundamente interiorizados, que contribui para definir, entre coisas, as atitudes face ao capital cultural e à instituiçẫo escolar" (BOURDIEU, 1996, p. 42).

${ }^{3} \mathrm{O}$ primeiro ginásio público da cidade de Campo Grande (MT), fundado em 1939, nasceu sob o nome Liceu Campograndense e, em 1942 passou a ser Colégio Campograndense; em 1953, nova alteração para Colégio Estadual Campograndense e, atualmente, Escola Estadual Maria Constança Barros Machado.

${ }^{4}$ É recorrente, em depoimentos e documentos da época, a importância atribuída à influência das professoras cuiabanas na história da educação em Campo Grande, na primeira metade do século XX, principalmente de Maria Constança Barros Machado (ARAÚJO, 1997).

\section{REFERÊNCIAS}

ADIMARI, Maria Fernandes. Escola e cidade: os sentidos dos espaços no Maria Constança, Campo Grande. 2005. 45 p. Dissertação (Mestrado em Educação)-Universidade Federal de Mato Grosso do Sul, Campo Grande, MS, 2005. 
ARAÚJO, Carla Busato Z. M. O ensino de didática, na década de trinta, no sul de Mato Grosso: ordem e controle? 1997. Dissertação (Mestrado em Educação)-Universidade Federal de Mato Grosso do Sul, Campo Grande, MS, 1997.

BITTAR, Marisa; FERREIRA JÚNIOR, Amarílio. De freguesia a capital: 100 anos da educação em Campo Grande. In: CAMPO Grande: 100 anos de construção. Campo Grande: Matriz, 1999. p. 195-236.

BOURDIEU, Pierre. A economia das trocas linguísticas. São Paulo: EDUSP, 1996.

BOURDIEU, Pierre. Estruturas, habitus e práticas. In: BOURDIEU, Pierre. Esboço de uma teoria da prática. Tradução de Miguel Serras Pereira. Oeiras: Celta, 2002. p. 163-184.

BRAGA, Horácio dos Santos. O ensino de latim na Escola Maria Constança Barros Machado como reflexo da história da disciplina no Brasil (1939-1971). 2005. 187 p. Dissertação (Mestrado em Educação)-Universidade Federal de Mato Grosso do Sul, Campo Grande, 2005.

BRAGA, Paulo Henrique A. A disciplina educaçâo física no Maria Constança: expressôes da cultura escolar no período de 1954-1964. 2006. 156 p.

Dissertação (Mestrado em Educação)-Universidade Federal de Mato Grosso do Sul, Campo Grande, 2006.

BRASIL. Decreto no 16.782-A, de 13 de janeiro de 1925. Estabelece o concurso da União para a difusão do ensino primário, organza o Departamento Nacional do Ensino, reforma o ensino secundário e superior e dá outras, providências. Diário Oficial da Uniāo, Rio de janeiro, 16 abr. 1925 .

BRASIL, Decreto n 21.241, de 4 de abril de 1932. Consolida as disposiçóes sobre a organização do ensino secundário e dá outras providências. Diário Oficial da União, Rio de janeiro, 9 abr. 1932.

BRASIL. Exposição de motivos da lei orgânica do ensino secundário, de $1^{\circ}$ de abril de 1942. In: BRASIL. Ensino Secundário no Brasil. Brasília: MEC/ INEP, 1952. p. 22-28. 
BRASIL. Lei n ${ }^{\circ}$ 5.692, de 11 de agosto de 1971. Fixa Diretrizes e Bases para o ensino de $1^{\circ}$ e $2^{\circ}$ graus, e dá outras providências. Diário Oficial da União, Brasília, DF, 18 ago. 1971.

BRASIL. Decreto-Lei n 4.244, de 9 de abril de 1942. Lei Orgânica do Ensino Secundário. In: VIEIRA, Sofia Lerche et al. Leis de reforma da educação no Brasil: Império e República. Brasília: INEP, 2008. p. 173-187. v. 2.

CAMPO GRANDE. Livro de registro de professores da Escola Maria Constaça de Barros. Campo Grande, MS, 1939.

CAMPO GRANDE. Arquivo da escola Maria Constança Barros Machado. Ata de Instalação da Escola Maria Constaça de Barros. Campo Grande, MS, 1953.

CAMPO GRANDE. Relatório da Escola Maria Constança de Barros. Campo Grande, MS, 1953.

CAMPO GRANDE. Relatório de verificação do Colégio Estadual Campograndense de Ensino Secundário. Campo Grande, MS, 1956.

DALLABRIDA, Norberto; CARMINATI, Celso João. O Tempo dos Ginásios: ensino secundário em Santa Catarina. São Paulo: Mercado das Letras, 2007.

HAIDAR, Maria de Lourdes Mariotto. O ensino secundário no Brasil Império. 2. ed. São Paulo: EDUSP, 2008.

MACHADO, Maria Constança Barros. Entrevista. In: SPOSITO, Marília Pontes. O povo vai à escola: a luta pela expansão do ensino público em São Paulo. São Paulo: Loyola, 1984.

MAGALHÂES, Justino P. Tecendo nexos: história das instituiçóes educativas. Bragança Paulista, SP: Editora Universitária São Francisco, 2004.

MATO GROSSO. Coleção das leis e decretos do Estado referente ao primeiro semestre do anno de 1938. Cuiabá: Impr. Oficial, 1938.

NUNES, Clarice. O "velho" e "bom" ensino secundário: momentos decisivos. Revista Brasileira de Educação, Rio de Janeiro, n. 14, maio/ago. 2000. p. 35-60. 
PESSANHA, Eurize Caldas; ARRUDA, Ângelo Marcos Vieira. Arquitetura escolar de "escolas exemplares" em quatro cidades brasileiras: expressão de projetos de modernização e escolarização de 1880 a 1954. Cadernos de História da Educação, Uberlândia, MG, v. 7, 2008.

RAHE, Marta Banducci. A disciplina língua inglesa e o "sotaque norteamericano": uma investigação das práticas docentes no Maria Constança (1955-2005). 2006. 145 p. Dissertação (Mestrado em Educação)Universidade Federal de Mato Grosso do Sul, Campo Grande, 2006.

ROSA, Maria da Glória. Memória da cultura e da educação em Mato Grosso do Sul. Campo Grande: Editora da UFMS, 1990.

VECCHIA, Ariclê. Formando cidadáos e líderes: o ensino secundário na província do Paraná. Revista HISTEDBR, Campinas, SP, v. 22, p. 54-70, jun. 2006.

ZOTTI, Solange Aparecida. Sociedade, educação e currículo no Brasil: dos jesuítas aos anos de 1980. Brasília, DF: Plano; Campinas, SP: Autores Associados, 2004. 


\section{La historia de una Institución Escolar: democratización o elitismo en la enseñanza secundaria de Brasil (1939- 1971)?}

\section{Resumen}

Este trabajo es un resultado de una investigación en el campo de la historia de las instituciones, que se centra en la reescritura de la historia de la educación secundaria. En ese contexto, interesa comprender el proceso histórico de implantación y consolidación de la educación secundaria en una escuela en el sur del estado de Mato Grosso, en el período comprendido entre 1939 y 1971. Este período fue determinado por la operación inicial de la escuela, y la Ley 5692 de 1971, que modificó la organización de la enseñanza primaria y secundaria en Brasil, lo que finalizando con el Gimnasio. Por lo tanto, a metodología propuesta combina los datos de la literatura, especialmente la relacionada con el tema de la educación secundaria, selección y análisis de libros, capítulos de libros, artículos y tesis de maestría y doctorado. Estas últimas, tuvieron como objeto de estudio la institución mencionada en este texto. También se realizó una investigación documental, y fueron seleccionados los documentos de origen en el archivo del Colegio Campograndense tales como: Actas de la Congregación, libros de actas, libros de exámenes de inscripción para la admisión al
The history of an scholar institution: democratization and elitism in Brazilian secondary education (19391971)?

\section{Abstract}

This paper presents the results of a research inserted in the field of the history of institutions, that is focused in rewriting the history of secondary education. In this context it is sought to understand the historical process of implementation and consolidation of secondary education in educational institution of the southern state of Mato Grosso in the period between 1939 and 1971. This period was determined by the beginning operation of the school and also by the Law 5692 of 1971, which changed the organization of primary and secondary education. So, to make this research the methodology used combines data from literature search on the secondary education as well as from the selection and analysis of books, chapters of books, academic articles, dissertation and theses. These latter were selected according to their object of study, the institution referred to in this text. Data from a documentary research has complemented this exercise, with documents selected in that school file, like: Congregation Reports; Minute Books; Registration Books for entrance exams; register books of teachers. It is pointed out, as a conclusion, that 
nivel inicial de secundaria o curso del Gimnasio, libros de registro de acceso y libros de registro de profesores. En conclusión la historia de esta institución indica que la "democratización" de la escuela contribuyó al ascenso social de las clases medias urbanas educadas que, apropiándose de este "lujo", permitieron insertarse a los grupos dirigentes.

Palabras claves: Instituciones Escolares. Educación Secundaria. Democratización de la Enseñanza.

\section{Eurize Caldas Pessanha}

E-mail eurize.pessanha@ufms.br

Fabiany de Cassia Tavares Silva

E-mail: fabiany.tavares@ufms.br this Institution's history indicates that the high school's "democratization" contributed to the social rise of the educated urban middle classes who, by appropriating this "luxury", were enabled to insert themselves into the group of leaders.

Keywords: Scholar institutions. Secondary education. Democratization of education.

Recebido em: 2/12/2012

Versão final recebida em: 6/9/2013

Aprovado em: 6/9/2013 